Адрес статьи / To link this article: http://cat.ifmo.ru/ru/2018/v3-i3/165

\title{
Информационная этика современного общества
}

\author{
И.И. Толстикова \\ Университет ИТМО, Россия \\ tolstikova_irina@mail.ru
}

\begin{abstract}
Аннотация. Рассматриваются актуальные инфоэтические проблемы, обусловленные разрывом между этическими принципами виртуальных коммуникаций и классическими моральноэтическими нормами. Влияние высоких технологий глобальной коммуникации на все сферы развития общества, в том числе на социокультурную сферу, обуславливает возрастающую потребность в этической верификации коммуникаций в виртуальном пространстве, новой информационной этике, в связи с расширением операционных возможностей и информационной мобильностью. Определяются границы поля межкультурной инфоэтики как с точки зрения наличествующих культурных традиций, восприятия инфокоммуникационных технологий различными культурами, так и с учетом межкультурных аспектов свободной глобальной коммуникации. Исследуются причины недостаточности цифровой компетентности детей, рассматривается влияние цифровой среды на становление личности.
\end{abstract}

Ключевые слова: информационное общество, этика, инфоэтика, этические проблемы, цифровая коммуникация, цифровая компетентность, цифровая компетентность детей.

\section{Введение}

Современное общество, в котором свобода доступа к информации гарантирована существованием новой инфраструктуры социальной коммуникации - сети Интернет, особенно актуализирует проблемы информационной этики. Наглядные трансформации общества как смена акцентов в общем стабильном составе его базовых характеристик демонстрируют необходимость осмысления проблем и нахождения решений в цифровую эпоху, вызывают вопрос о роли моральных установлений в реалиях XXI века.

Влияние высоких технологий глобальной коммуникации на все сферы развития общества, в том числе на социокультурную сферу, обуславливает возрастающую потребность в этической верификации коммуникаций в виртуальном пространстве; новой информационной этике - в связи с расширением операционных возможностей и информационной мобильностью.

В работе «Критика практического разума» И. Кант писал: «Две вещи наполняют душу всегда новым и все более сильным удивлением и благоговением, чем чаще и продолжительнее мы размышляем о них, - это звездное небо надо мной и моральный закон во мне» [5].

Начиная со второй половины XX века, информационная этика становится устойчивым направлением философского знания. С конца XX века кризисные явления в сфере общественной 
морали в условиях глобальной коммуникации формулируются как проблемы информационной этики, моральной ответственности, цифрового неравенства, свободы коммуникации, проблемы соблюдения прав человека и сохранения неприкосновенности частной жизни человека в цифровую эпоху. Базовые нормы общества, как правило, не коррелируются с устремлениями пользователей сетей к свободному выражению своего мнения, проявлению индивидуальности, свободе обмена информацией. Исследователи из разных стран фокусировались на принципах допустимого использования интернета. Создана достаточно серьезная база фундаментальных теоретических исследований информационной этики. Однако также необходимо отвлечение от теоретической аксиологии современной информационной этики в пользу рассмотрения факторов трансформации традиционной этики и самой жизни людей в цифровую эпоху для определения моральных дилемм информационного общества.

Свобода слова, свобода печати и свобода доступа к информации, а также регулирование поведения человека в условиях неиерархической глобальной среды - таковы основные направления информационной этики. Начиная с работ М. Хайдеггера, К. Ясперса, Х. Ортега-иГассета и других, когда в русле философии техники осмысливались проблемы, связанные с развитием техники и изменением роли и места человека в технической цивилизации, формируются аксиологические основания современного информационного общества.

Классические исследования информационного общества, проведенные Э. Тоффлером, М. Кастельсом, И. Масудой и другими, дают прорисовку профиля информационного общества с точки зрения социального прогнозирования. Во второй половине XX века этические проблемы, связанные с возрастанием социальной значимости развития информационных технологий, становятся еще более очевидными и привлекают все большее внимание [2].

Создание периодизаций становления информационного общества приводит к осознанию духовной парадигмы информационного общества как нравственного идеала. Примером может послужить периодизация от протоинформационного периода (30-50-е гг. XX века); проектного периода (60-90-е гг. XX века) до критического периода (рубеж XX-XXI веков) В.А. Возчикова, предложенная им в своей монографии [3].

\section{Определение проблематики инфоэтики}

Процесс формирования классических морально-этических норм поведения и правил общения шел на протяжении длительного периода становления и развития общества, корректировался по мере изменения социально-экономических институтов и государственного устройства. Со стремительным появлением принципиально новых форм коммуникации в глобальном информационном пространстве, таких как Интернет, сотовая связь и тому подобного, становится очевидным, что инфоэтические принципы виртуальных коммуникаций нуждаются в осмыслении, проработке и легитимизации. Интернет превратился в основную инфраструктуру взаимодействия людей. В этом смысле становится очевидным влияние информационных технологий на социальную коммуникацию и на все современное общество. М. Кастельс в книге «Галактика Интернет» писал об Интернете как о «средстве свободной глобальной коммуникации» [7].

Воздействие цифровых технологий на общество и окружающую среду, вся информационная и коммуникационная среда - это сфера рассмотрений инфоэтики. Основными проблемами инфоэтики являются вопросы свободы, безопасности, дискриминации, конфиденциальности частной жизни, интеллектуальной собственности, достоверности информации, цензуры, межкультурного общения и нахождения устойчивых решений в цифровую эпоху.

«Новые этические и правовые решения в таких условиях необходимы для баланса потребностей и прав каждого человека, а выработка и принятие инфоэтических принципов должны заполнить пробел, образовавшийся из-за того, что правовые решения и культура пользователей сегодня значительно отстают от стремительного развития информационных технологий. Инфоэтика определяется общими принципами доступа, справедливости и взаимного уважения, связанными с развитием и использованием информационных технологий. Эти проблемы все чаще обсуждаются, вызывают большой интерес, включают вопросы формирования доверия граждан к электронному правительству, прав собственности и ценности информации,

Культура и технологии, Том 3, № 3 
неприкосновенности личной жизни, конфиденциальности и информационной безопасности, распространения экстремизма, ненависти и насилия в Интернете и т.п.» [4].

Основные и текущие задачи инфоэтики как важнейшего междисциплинарного и межкультурного направления, отражающего трансформации человечества посредством компьютерных технологий, были практически сформулированы еще в 2007 г. в докладе «Оставаясь людьми: взаимодействие между людьми и компьютерами в 2020 году» (Being Human: Human-computer interaction in the year 2020) по итогам совещания, организованного в 2007 году исследовательским подразделением корпорации Microsoft: «Новые технологии допускают новые формы контроля или децентрализации, поощряя определенные виды социального общения в ущерб другим и пропагандируя определенные ценности, отрицая их альтернативы. Например, iPod можно рассматривать, как устройство, олицетворяющее безразличие жителей городов, мобильный телефон - как устройство, способствующее болезненной потребности в социальных контактах, а Всемирную паутину - как нечто подрывающее традиционные формы власти. Нейронные сети, алгоритмы распознавания и интеллектуальный анализ данных - все эти технологии оказывают воздействие на культуру. Эти воздействия необходимо осознавать в более широком контексте, выходя за рамки чисто технических возможностей. Конечный вывод состоит в том, что компьютерные технологии не нейтральны - они наполнены человеческими, культурными и социальными ценностями. Эти ценности можно предсказывать и учитывать, они могут появляться и эволюционировать после многих проб и ошибок. В поликультурном мире мы также должны признать, что часто могут возникать конфликтующие системы ценностей. В будущих исследованиях необходимо сделать упор на создание более широкой и перспективной концепции того, что означает быть человеком в потоке идущих сейчас преобразований» [13].

Сущностные характеристики сетевого пространства, к которым относятся глобальность, анонимность, быстрая воспроизводимость данных, доступность, интерактивность и практически бесконтрольность, порождают множество проблем, связанных с кризисом общественной морали. При этом необходимо учитывать неоднородность сетевого пространства, которое принято разделять, по меньшей мере, на четыре сектора: поиск информации, развлечения, бизнескоммуникация и общение, при рассмотрении нравственных принципов виртуального взаимодействия. Фактически остается неразработанным вопрос о наличии специфических принципов, норм и методов оценки различных действий в сети, которые существенным образом отличались бы от представленных в традиционной этике.

\section{Определение поля межкультурной информационной этики}

Одним из новых терминов, введенных десятилетие назад, является понятие межкультурной информационной этики, отражающее сложный динамизм этого поля изучения. Один из исследователей инфоэтики, Р. Капурро, в своей работе «Межкультурная информационная этика» дает определение межкультурной информационной этики как «бытия-в-мире-с-другими» и выделяет такие объекты этической оценки, как «интеллектуальная собственность, неприкосновенность частной жизни, безопасность, перегруженность информацией, цифровой разрыв, дискриминация по признаку пола, искусственные “посредники”, виртуальная реальность, робототехника, достоверная и актуальная информация об окружающей среде и цензура... Все это относится к объектам тщательной этической оценки не только с точки зрения всеобщих прав и принципов, но и с точки зрения различий между культурами, исторических и географических особенностей» [12]. В своем программном выступлении на тему «Межкультурная информационная этика» Р. Капурро поднял важные вопросы об основах философии и этики и принятом подходе к ее корням как исторически западным. Западная философия имеет сильные традиции в европейской и особенно ранней греческой истории.

В нашем глобальном информационном обществе было бы достаточно проблематично утверждать, что основа этики, в частности информационной этики, лежит исключительно в западной традиции. Если мы попытаемся создать подлинный диалог об этических ценностях и этических причинах в мультикультурном мире Интернета, мы не сможем придерживаться исключительно этой традиции, потому что, например, китайцы и индийцы вовлечены в этическую мысль и этические рассуждения, и их основания для разрешения этических дилемм не всегда будут соответствовать тем, которые, которые предлагаются в западном обществе. Для подлинно межкультурной информационной этики нужно серьезно относиться к разнообразным культурам

International Culture \& Technology Studies, Vol. 3, No. 3 
мира и их историческим традициям. Это также включает феминистскую перспективу, которая долгое время игнорировалась или недооценивалась как в западной, так и в восточной культурах.

Используя подходы данного исследования, можно предположить границы поля межкультурной инфоэтики как с точки зрения наличествующих культурных традиций, восприятия инфокоммуникационных технологий различными культурами, так и с учетом межкультурных аспектов свободной глобальной коммуникации. Использование метода сопоставления исторического, культурного, - является одной из важных характеристик межкультурной инфоэтики. Термин «паррезия» (от греч. «свобода слова»), описанный М. Фуко как выбор в пользу свободы, откровенности, истины и морального долга, вводится Р. Капурро для интерпретации взаимовлияния различных культур и их традиций, в том числе, научных и литературных рефлексий. Понимание межкультурной информационной этики, которая свободна от предлагаемых западноевропейской культурой ценностей и традиций, приводит к созданию и ведению поликультурного диалога об этических ценностях.

Таким образом, межкультурная информационная этика может быть рассмотрена как этика мультикультурного мира, исследующая «моральные вопросы отражения различных культурных традиций в информационной среде».

Одна из важнейших проблем цифровой этики — «цифровое неравенство» - должна также рассматриваться в рамках межкультурной информационной этики, так как, независимо от потребностей, интересов и культурных традиций, должно быть гарантировано право на реализацию возможностей открытого информационного общества.

Цифровая глобализация может обеспечить коммуникацию в едином мире, совокупность взаимоотношений, стать исходной точкой поиска общих этических принципов на основе сохранения, интерпретации и применения особенностей отдельных культур.

\section{Цифровая компетентность детей}

Особую актуальность рассмотренные проблемы приобретают, когда речь идет о подрастающем поколении и их вхождении в сложную систему общественных отношений, находящуюся в процессе трансформаций в результате происходящих глобальных изменений. Сфера образования играет важную роль в подготовке детей, молодежи и взрослых к вызовам и возможностям во все более цифровизующемся обществе. Реальность информационного общества создает принципиально новые формы и виды взаимодействия людей, где простая экстраполяция в область виртуальной социальности традиционных схем и законов вызывает недоверие. Интернеттехнологии - это не просто инструмент для применения, а процессы, которые следует развивать. Цифровое развитие затрагивает все аспекты жизни общества, как коллективные, так и индивидуальные, и приносит с собой новые возможности, а также проблемы. Возможности сбора и обмена информацией и данными огромны и требуют высоких стандартов безопасности и защиты, а также разумного использования и распространения информации. Этого требуют изменения в сфере трудовой деятельности, в организации процесса обучения в учебных заведениях, этого требует практика межличностной и межкультурной коммуникации. Поэтому все - и стар, и млад - должны проходить процесс адаптации и становиться как компетентным пользователем (рис. 1), так и критически важным потребителем. Более того, развитие искусственного интеллекта дает концепции совсем другое измерение. «В совокупности эти изменения приведут к радикальному преобразованию как мира бизнеса, так и повседневной жизни» [1].

Наряду с общими проблемами цифровой компетентности, к которым относятся способность человека эффективно и критично использовать цифровые технологии в разных сферах деятельности, особенное внимание необходимо уделить ценностной сфере личности ребенка, этическим правилам поведения и норм безопасности. В оборот вводится понятие «цифровое гражданство» [10], которое подразумевает как владение цифровыми технологиями, так и культуру сетевого общения. По результатам всероссийского исследования цифровой компетентности подростков и родителей, которое проводилось в 2012-2013 годах Фондом Развития Интернет и факультетом психологии МГУ имени М. В. Ломоносова при поддержке компании Google, уровень цифровой компетентности подростков и родителей составляет примерно треть от максимально возможного. Использование цифровых технологий для обучения

Культура и технологии, Том 3, № 3 
в школах улучшает восприятие родителями этих технологий, что, в свою очередь, помогает детям в цифровом обучении и поддерживает более здоровое и более осмысленное использование цифровых устройств. Отношение родителей к цифровым технологиям формирует среду обучения и отношение детей. При этом, родители видят цифровую эволюцию как неизбежную, но очень сложную. Отношение родителей к цифровым технологиям играет важную роль в стратегиях, которые они принимают в отношении использования цифровых инструментов своими детьми, и, следовательно, также в формировании цифровых навыков своих детей. Родительские стратегии использования детьми цифровых устройств - открытые, разрешительные, поддерживающие, ограничительные - основаны на многочисленных взаимосвязанных факторах, от навыков, знаний, отношения и восприятия родителей в отношении цифровых технологий до их личного опыта и социально-экономических обстоятельств.

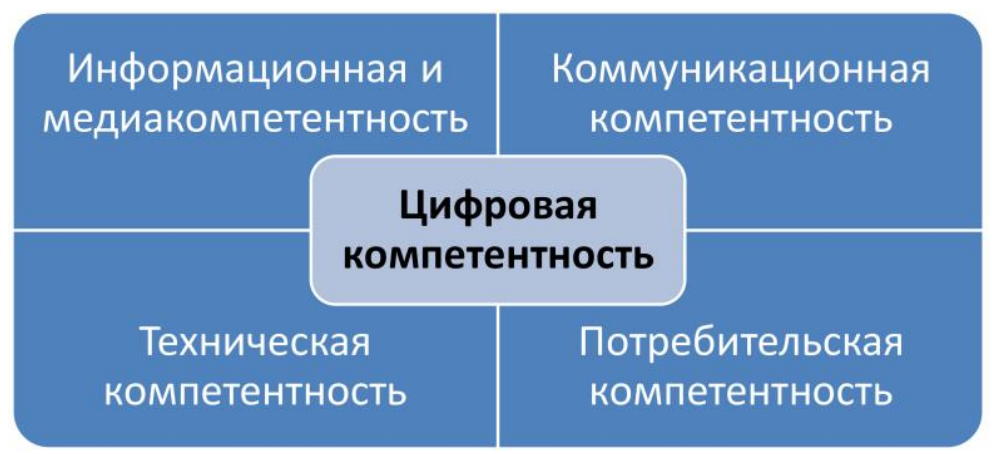

Рис. 1. Виды цифровой компетентности

Средний уровень знаний составляет не более половины от максимально возможного, а мотивация - только 20 процентов. Собственные же представления о своей цифровой компетенции составляют около 80 процентов у подростков и 50 процентов - у родителей [11].

Одной из важнейших причин недостаточности цифровой компетентности является отсутствие системы обучения использования интернета, самостоятельное изучение интернета вне диалога и рефлексии.

Важно обратить внимание на изменения памяти, внимания и мышления, связанные с высшими психологическими функциями и формированием других механизмов удержания информации, снижением концентрации внимания и переработкой информации короткими порциями. «Феномен клипового мышления - признак того, что мы переживаем важнейший момент в нашей интеллектуальной и культурной истории - момент перехода от одной модели мышления - линейной - к другой, совершенно на нее не похожей — сетевой» [6].

Рассматривая влияние цифровой среды на становление личности, необходимо отметить изменения языковой ситуации. Наряду с положительными тенденциями, такими как развитие способности к самовыражению на разных платформах, обращение к широкой аудитории, отмечается отсутствие навыков использования стилей, соответствующих аудитории, обеднение словарного запаса, стирание граней между формальным и неформальным стилями речи, упрощенные и стандартизированные формы общения. То есть, мы вынуждены констатировать изменение ландшафта письма, которое также является следствием расширением доступности информации в цифровизированном обществе. Если ранее, при обращении к книге, предоставленная информация была проверена и легализована, то сейчас велика вероятность получения информации, которая является необоснованной или просто неверной. И, как следствие подобного развития языковой личности, утрата способности критического мышления.

Исследования влияния цифровых устройств на формирование языковой личности проводятся в России и других странах достаточно давно, но результаты пока не выходят на положительную динамику. Так, в 2012 г. в исследовании американского исследовательского центра по изучению Интернета и общественной жизни Pew Research Center «Влияние цифровых устройств на письменную речь школьников и как она преподается в школах» («The Impact of Digital Tools on Student Writing and How Writing is Taught in Schools») приводятся данные, полученные в результате on-line опроса 2462 американских учителей, работающих со школьниками средних и старших классов, и работы с фокус-группами учителей. По девяти

International Culture \& Technology Studies, Vol. 3, No. 3 
навыкам, отражающим владение культурой речи, учителя поставили оценки «удовлетворительно» (3) или «хорошо» (4) по пяти-бальной системе. Перечислим эти навыки: эффективно организовывать и структурировать текст, понимать и оценивать различные точки зрения, давать конструктивные отзывы, уметь корректно привести цитату или ссылку, умение создавать цельный текст на основе информации из разных источников, использовать тон и стиль, уместный для данной целевой аудитории, приводить сильные аргументы, читать длинные и сложные тексты, уделять внимание добросовестному использованию и соблюдению авторских прав [8].

В современном обществе человек является не просто пользователем цифрового мира, который должен знать и уметь воспринимать такие атрибуции, как разнородность, сложность, неоднозначность, неопределенность, но и обладать другой половиной цифровой компетентности — мотивацией и ответственностью в обществе «текучей современности» [9].

\section{Выводы}

Информация и информационные технологии приобретают все большее значение для нашего социального, экономического и политического взаимодействия. Учитывая это, настала пора серьезно задуматься об информационной этике, которая изучает аксиологические аспекты работы с информацией - возникающие при создании, контроле и доступе к информации. Таким образом, инфоэтика - актуальное научное направление, исследующее современные моральные проблемы общества глобальных коммуникаций. Сущностные характеристики сетевого пространства, к которым относятся глобальность, анонимность, быстрая воспроизводимость данных, доступность, интерактивность и практически бесконтрольность, порождают множество проблем, связанных с кризисом общественной морали.

Межкультурная информационная этика может быть рассмотрена как этика мультикультурного мира, исследующая «моральные вопросы отражения различных культурных традиций в информационной среде». Цифровая глобализация может обеспечить коммуникацию в едином мире, совокупность взаимоотношений, стать исходной точкой поиска общих этических принципов на основе сохранения, интерпретации и применения особенностей отдельных культур.

Особую актуальность рассмотренные проблемы приобретают, когда речь идет о подрастающем поколении и их вхождении в сложную систему общественных отношений. Наряду с общими проблемами цифровой компетентности, к которым относятся способность человека эффективно и критично использовать цифровые технологии в разных сферах деятельности, особенное внимание необходимо уделять ценностной сфере личности ребенка, этическим правилам поведения и норм безопасности детей.

\section{Литература}

[1] Гейтс Б. Бизнес со скоростью мысли. - М., 2001. С. 43.

[2] Вейценбаум Дж. Возможности вычислительных машин и человеческий разум. От суждений к вычислениям. Пер. с англ. М., 1982.

[3] Возчиков В.А. Медиасфера философии образования. Бийск: БПГУ им. В. М. Шукшина, 2007. - 284 с.

[4] Овчинников С. А., Гришин С. Е. Информационно-этические проблемы построения информационного общества. URL: https://cyberleninka.ru/article/n/informatsionno-eticheskie-problemy-postroeniyainformatsionnogo-obschestva (дата обращения: 20.11.2017).

[5] Кант И. Критика практического разума. Соч. в шести томах, Мысль, 1965. (Философ. наследие). - Т. 4. Ч. I. - C.499.

[6] Карр Н. Пустышка. Что интернет делает с нашими мозгами. M.: BestBusinessBooks, 2012. - С. 253.

[7] Кастельс, М. Галактика Интернет: размышления об Интернете, бизнесе и о-ве / Мануэль Кастельс ; [пер. с англ. А. Матвеева под ред. В. Харитонова]. - Екатеринбург : У-Фактория : Изд-во Гуманитарного унта, 2004. $-327 \mathrm{c}$.

[8] Солдатова Г. В. Соблазны копипаста. Как цифровая среда влияет на становление языковой личности// Дети в информационном обществе, 2013. № 14. С.42-49.

[9] Солдатова Г., Зотова Е., Лебешева М., Шляпников В. Интернет: возможности, компетенции, безопасность. М.: Google, 2013. С. 18.

[10] Солдатова Г. В., Нестик Т. А., Рассказова Е. И., Зотова Е. Ю. Цифровая компетентность подростков и родителей: результаты всероссийского исследования. - М., Фонд Развития Интернет, 2013.

[11]Солдатова Г. В., Рассказова Е. И., Зотова Е. Ю. Аборигены или граждане?//Дети в информационном обществе, 2013. № 13. С.13-51.

Культура и технологии, Том 3, № 3 
[12] Capurro R. Intercultural Information Ethics. In: Kenneth E. Himma, Kenneth Einar and Herman Tavani (Eds.): The Handbook of Information and Computer Ethics. Hoboken, New Jersey: Wiley, 2008. P. 639-665. URL:http://emag.iis.ru/arc/infosoc/emag.nsf/BPA/ 7c972fbe98fca119c32577dc0036bb4f (дата обращения: 11.01.2018).

[13] Harper R., Rodden T., Rogers Y., Sellen A. Being Human: Human-Computer Interaction in the Year 2020. Microsoft Corporation, 2008. URL: http://research.microsoft.com/enus/um/cambridge/projects/hci2020/downloads/beinghuman_a4.pdf, с. 57 (дата обращения: 11.01.2018).

\title{
Information Ethics of Modern Society
}

\author{
I.I. Tolstikova
}

ITMO University, Russia

\begin{abstract}
The article considers actual infoethical problems caused by the gap between the ethical principles of virtual communications and classical moral and ethical norms. The influence of high technologies of global communication on all spheres of social development, including the sociocultural sphere, causes an increasing need for ethical verification of communications in the virtual space, new information ethics, due to the expansion of operational opportunities and information mobility. The boundaries of the field of intercultural infoethics are defined both in terms of existing cultural traditions, perception of information and communication technologies by different cultures, and took into account the intercultural aspects of free global communication. The reasons for the lack of children digital competence are examined, the influence of the digital environment on the development of a personality is considered.
\end{abstract}

Keywords: information society, ethics, infoethics, ethics problems, digital communication, digital competence of children

\section{References}

[1] Gates B. (2001) Business at the Speed of Thought. M. 43.

[2] Weizenbaum J.(19820 Capabilities of computers and the human mind. From judgment to computation.

[3] Vozchikov V.A. (2007) Media sphere of educational philosophy.

[4] Ovchinnikov S.A., Grishin S.E. Informational and ethical problems of building the information society. Available at: https://cyberleninka.ru/article/n/informatsionno-eticheskie-problemy-postroeniyainformatsionnogo-obschestva (access date: 20/11/.2017).

[5] Kant I. (1965) Criticism of practical reason. Cit. in six volumes. (Philosoph. Heritage). - T. 4. Part I. 499.

[6] Carr N. (2012). The Shallows: What the Internet is doing to our brains. BestBusinessBooks. 253.

[7] Castells M. (2004). The Internet Galaxy: Reflections on the Internet, Business, and Society (Clarendon Lectures in Management Studies. 327.

[8] Soldatova G.V. (2013). The temptations of copy-paste. How does the digital environment influence the development of a language identity? Children in the information society, 14. 42-49.

[9] Soldatova G., Zotova E., Lebeshesheva M., Shlyapnikov V. (2013). Internet: capabilities, competencies, security. 18 .

[10] Soldatova G. V., Nestik T. A., Rasskazova E. I., Zotova E. Yu. (2013). Digital competence of adolescents and parents: the results of a nationwide study.

[11] Soldatova G. V., Rasskazova E. I., Zotova E. Yu. (2013) Aboriginal people or citizens? Children in the information society, 13. 13-51.

[12] Capurro R. (2008). Intercultural Information Ethics. In: Kenneth E. Himma, Kenneth Einar and Herman Tavani (Eds.): The Handbook of Information and Computer Ethics. Hoboken, New Jersey: Wiley, 2008. P. 639-665. Available at: http://emag.iis.ru/arc/infosoc/emag.nsf/BPA/ 7c972fbe98fca119c32577dc0036bb4f (access date: 11/01/2018).

[13] Harper R., Rodden T., Rogers Y., Sellen A. (2008). Being Human: Human-Computer Interaction in the Year 2020. Available at: http://research.microsoft.com/enus/um/cambridge/projects/hci2020/downloads/beinghuman_a4. pdf, 57 (access date: 11/01/2018). 